\title{
ADOLESCENT TOBACCO USE ESTIMATES FROM THE GLOBAL YOUTH TOBACCO SURVEY, INDIA: TOBACCO A RISK FACTOR FOR FUTURE SPREAD OF COVID 19
}

\author{
Khushbu Sharma, Mangesh S. Pednekar \\ Healis, Sekhsaria Institute for Public Health, Navi Mumbai, Maharashtra 400701, India
}

Correspondence: sharmak@healis.org

\begin{abstract}
BACKGROUND:

Tobacco use has been identified as a risk factor and causes negative outcomes to the COVID 19 pandemic. Adolescents' tobacco users in India are the vulnerable population to acquire COVID-19 in the future. The study aimed to understand tobacco consumption patterns among adolescents in India to highlight the vulnerability of this population to COVID-19 infection.
\end{abstract}

\section{METHODS:}

The Global Youth Tobacco Survey (GYTS) reports were identified and recovered from the Centre for Disease Control and Prevention (CDC) data sets. The findings of the surveys in 2003, 2006, and 2009 were compared with respect to the prevalence of cigarette smoking and other tobacco use, and the determinants of initiation of tobacco use among the adolescent population.

\section{RESULTS:}

The total tobacco consumption among adolescents was found to have increased from $13.7 \%$ in 2006 to $14.6 \%$ in 2009. All forms of tobacco use were higher in boys than girls across all three survey periods. Also, the trend of bidi (smoked tobacco form) use had increased in both genders. A reduction in exposure to Secondhand Smoke, with an increase in cessation services, media campaigns, and tobacco-related school curriculum was noted. If the increase in tobacco consumption between 2006 and 2009 had continued at the same rate, then in 2021 around $18 \%$ of adolescents are estimated to consume tobacco in some form.

\section{CONCLUSION:}

The significant overall tobacco use and increasing bidi consumption makes the adolescent group more susceptible to COVID-19 infection. This indicates an imperative need to include this age group for COVID-19 management to reduce the burden on health care.

\section{KEYWORDS}

Adolescent, Tobacco use, COVID-19, Health systems, India 
in the future. They will constitute the vulnerable population for the NCDs and be prone to COVID 19 infections as well.

Coronavirus disease 2019 (COVID-19), has spread around the world and caused by severe acute respiratory syndrome coronavirus 2 (SARS- CoV-2). [1] The virus primarily affects the lung epithelial cells and causes viral pneumonia and acute respiratory distress syndrome. [2] The scientific community is constantly estimating the clinical characteristics of the disease and the prognostic factors. Tobacco has been identified to be associated with the negative progression, a positive diagnosis, high hospitalization rates, and exacerbated health outcomes of COVID-19. [3] [1] [4]

Tobacco has an established impact on lung function and reduces the immune efficiency of the body, that in turn, makes the users prone to respiratory infections such as COVID-19. [5] The use of tobacco products causes a high chance of transmission of the COVID- 19 virus. This is because of, contaminated fingers, constant touching of the face and mouth while use, sharing of the products, social gathering for smoking in closed environments, and spitting of the smokeless tobacco form. [6,7] COVID- 19 related mortality and morbidity are severe with higher rate among those with comorbidities such as noncommunicable diseases (NCDs) including hypertension, diabetes, and chronic obstructive pulmonary disease COPD. [6] There is significant evidence stating the role of tobacco as a risk factor in the causation of the NCDs. [8] In addition a meta-analysis had reported a strong relationship between the history of smoking and severe COVID-19 cases with higher odds among smokers than the nonsmokers. [9]

The recent COVID- 19 data in India indicates that the second wave of the pandemic is taking a toll on the younger age groups. The national statistics state, among the current COVID- 19 patients about $8.14 \%$ are in the age group of 11-20 years and $22 \%$ are in the 20 to 40 years of age group. [10] Visualising the younger generation scum to the pandemic, primary risk factors need to be identified and addressed. India is the second-largest consumer of tobacco in the world and the consumption patterns among adolescents are alarming. [11] The youth in India have reported initiating tobacco consumption at an early age of 15 years, resulting in a habit formation by the time they are adults. [12] Also, the youth, who are the current tobacco users, will constitute the adult tobacco consumers

The health and economic burden related to tobacco globally is a known fact and now the mortality due to COVID - 19 has increased resulting in an additional burden on the health systems of the countries. [13] The low and middle-income countries (LMIC) have already been struggling under the burden of tobacco-related illness and death and are now unable to cope with the difficult COVID-19 circumstances. Given the burden, countries like India are facing challenges in rendering health care services with workforce shortages, absenteeism, poor infrastructure and quality of care, and inefficient health systems. [14] To address the substantial projection of the COVID -19 burden due to the extensive tobacco use in India, the country needs to identify the risk groups and adopt appropriate strategies.

With the link between tobacco use and the spread of COVID 19, it is essential to comprehend the consumption patterns and factors associated with tobacco use among the adolescent age group. This will provide a strong insight on how to integrate the present tobacco control policies into COVID -19 programmes. With this background, the present study aimed to understand the tobacco consumption patterns among adolescents in India to highlight the vulnerability of this population to COVID-19 infection. With this aim, we have studied and compared the trends and patterns of tobacco consumption and related factors among adolescents, using the Global Youth Tobacco Survey, India.

\section{METHODS}

The study used nationally representative data on youth in India collected through the Global Youth Tobacco Surveys. In the view of systematic monitoring and surveillance of tobacco use among youth, the Global Youth Tobacco Survey (GYTS) is carried out under the Global Tobacco Surveillance System (GTSS). [15] The GYTS in India has been conducted in 2003, 2006, and 2009 wherein the students of grades 8,9 and 10 were surveyed. The survey collected data on the prevalence of tobacco use (smoking and smokeless) among the school students. It also recorded information about factors that influence adolescents to initiate tobacco consumption. [16] 
The GYTS survey reports of 2003, [16] 2006 [17] and 2009 [18] were identified and recovered from the Centre for Disease Control and Prevention (CDC) data sets. Therefore, no ethical review was required for the study. The survey findings were compared with respect to the prevalence of cigarette smoking and other tobacco use and the determinants of tobacco initiation and use among adolescents. The determinants of tobacco use were exposure to secondhand smoke (SHS), cessation of cigarette smoking, media and advertising, access and availability of cigarettes, and tobacco-related school curriculum.

\section{RESULTS}

The survey findings, which could significantly aid future recommendations to reduce the susceptibility of this young population to COVID- 19 were identified and reported.

\section{TOBACCO PREVALENCE TRENDS AMONG ADOLESCENTS:}

The total tobacco consumption among adolescents was found to be $16.9 \%$ in $2003,13.7 \%$ in 2006 , and $14.6 \%$ in 2009
(Table 1). Overall, both forms of tobacco were found to be consumed by the adolescent age group. Although the total (Table1) and gender-wise smokeless form consumption had declined over the years it was consumed at a higher rate than the smoking form. Boys consumed both smoking and smokeless form more than girls across all three survey periods. The reports revealed the following gender-wise distribution; (1) Smokeless form: 2003 (B-18.0\%, G-7.9\%), 2006 (B- 10.7\%, G- 7.5\%), and 2009 (B- 11.1\%, G6.0\%), and (2) Smoking form : 2003 (B-10.5\%, G- 4.2\%), 2006 (B-9.4\%, G- 3.6\%), and 2009 (B-11.2\%, G-3.7\%). Also, the comparisons among the smoking form revealed that both cigarette smoking from 2003 (B-5.7\%, G-1.8\%) to 2009 (B 5.8$\%$, G-2.4\%) and bidi (smoked tobacco form made by rolling a dried, rectangular piece of temburni leaf (Diospyros melanoxylon) with $0.150 .25 \mathrm{~g}$ of sun-dried, flaked tobacco into a conical shape and securing the roll with a thread [19]) consumption from 2003 (B- 2.9\%, G-1.1\%) to 2009 (B7.3\%, G-2.2\%) had increased. Furthermore, in 2009, the last survey there were at least $15.5 \%$ of non-smokers, who had reported to start smoking by the end of next year.

TABLE 1: TOBACCO PREVALENCE AMONG ADOLESCENTS

\begin{tabular}{|l|l|l|l|}
\hline TOBACCO FORM & $\mathbf{2 0 0 3}(\boldsymbol{\%})$ & $\mathbf{2 0 0 6}(\boldsymbol{\%})$ & $\mathbf{2 0 0 9}(\mathbf{\%})$ \\
\hline Total current tobacco use & 16.9 & 13.7 & 14.6 \\
\hline Smoking form & 8.1 & 7.0 & 8.1 \\
\hline Smokeless form use & 14.0 & 9.4 & 9.0 \\
\hline
\end{tabular}

\section{DETERMINANTS OF TOBACCO USE AMONG ADOLESCENTS:}

\section{Exposure to secondhand smoke}

Overall (Table 2) the exposure to secondhand smoke (SHS) at home and in public places had reduced for both genders [20] [21] from 2003 to 2009. Furthermore, the number of people who thought smoking in public places should be banned and smoke from others was harmful was significant, with a minor decline in percentages as follows, 2003 (74.8\%), 2006(74.0\%), and 2009(63.3\%).

\section{Cessation of cigarette smoking}

Although, two-thirds of the students reported that they wanted to stop smoking immediately, the proportion was highest in 2006 (70.3\%) than in 2009 (66\%). The help utilized for smoking cessation including both the boy and girls had significantly increased in 2009 since 2003 (Table 2). Consistent use of cessation services utilization had also resulted in $67.2 \%$ of the adolescent who tried to stop smoking in 2009. Also, 2009 (19.5\%) had the highest increase in the percentage of ever smokers, who had received help or advice to quit smoking from various means, such as program, professionals, family members or friends. 
TABLE 2: DETERMINANTS OF TOBACCO USE AMONG ADOLESCENTS

\begin{tabular}{|l|l|l|l|}
\hline DETERMINANTS & $\mathbf{2 0 0 3}(\mathbf{\%})$ & $\mathbf{2 0 0 6}(\%)$ & $\mathbf{2 0 0 9}(\%)$ \\
\hline Exposure to secondhand smoke at home & 36.2 & 26.6 & 21.9 \\
\hline Exposure to second-hand smoke in public places & 48.8 & 40.3 & 36.6 \\
\hline Cessation services used & 84.6 & 81.8 & 94.3 \\
\hline Media and advertising- view anti-smoking messages & NA & 74.0 & 77.5 \\
\hline $\begin{array}{l}\text { Access and availability of cigarettes- who bought cigarette in a } \\
\text { store }\end{array}$ & 64.8 & 51.9 & 47.0 \\
\hline Tobacco-related school curriculum- dangers of tobacco & 52.3 & 54.4 & 63.3 \\
\hline
\end{tabular}

\section{Media and Advertising}

The exposure to anti-smoking media messages in the past 30 days also had consistently increased since 2003 with the highest in 2009 (Table 2). Furthermore, the exposure to procigarette advertisements on billboards had also increased in 2009 (74.4\%) since 2003 (42.1\%). The numbers indicate a progressively growing issue of tobacco marketing for this age group.

\section{Access and availability of cigarettes}

Overall, the current users buying cigarettes in a store had significantly decreased from 2003 to 2009 (Table 2). Also, there was a consistency in the percentage of students offered free cigarettes between 2003 (8.1\%) and 2009 (8.1\%). Furthermore, the percentage of students who purchased cigarettes in a store without being refused had seen a decline with $55.3 \%, 72.1 \%$, and $56.2 \%$ in 2003,2006 , and 2009 respectively.

\section{Tobacco-related school curriculum}

The inclusion of dangers of smoking in the school curriculum had substantially increased over the years. (Table 2) The school curriculum had predominately included information related to the dangers of tobacco, reasons for smoking, and effects of tobacco use. The discussion about reasons why young people smoke had remained consistent over the survey years, but the discussion on the effects of tobacco in the class was highest in 2009 (55.9\%) in comparison to the previous years.

\section{DISCUSSION AND CONCLUSION}

The comparison of the GYTS reports indicates that total tobacco consumption has increased by $6.57 \%$ in 2009 compared to 2006. Identifying the lack of any recent national representative survey on adolescent since 2009, if the increase in tobacco consumption between 2006 and 2009 had continued at the same rate then in 2021 around $18 \%$ of adolescents are estimated to consume tobacco in some form. Also, an additional $15.5 \%$ of never smokers who reported in 2009 the likeliness to initiate smoking from the next year might significantly add to the current tobacco users in this population. The secondary analysis of the GYTS survey of the Indian adolescent age group predominately points to prevalent tobacco use among the adolescent population. Extrapolating the findings from literature and the current COVID -19 age-wise distribution, tobacco use in this age group should be attention seeking for future coronavirus disease burden.

The high use of smoking and smokeless form of tobacco in this population and its association with the modes of spread of the COVID- 19 virus brings the health system to a 'worrisome' state. The transmission, mortality, and morbidity rates will be expected to rise drastically due to the increased susceptibility of these current young tobacco users in the future. The increased use of bidi in this population indicates the high use in the low socioeconomic population who are unaware of the risks related to tobacco and COVID-19 infection, and with limited health care services around them will add to the enormous health burden to the country.

Currently, the COVID management strategies are targeted towards the older adults with complete lack of attention towards this population. The study emphasizes including this young population in the regimen of care for future planning of COVID 19 management. Furthermore, integration of the tobacco control policies into COVID-19 strategies is 
required. India already has a widespread National Tobacco Control Programme based on the WHO- FCTC and the MPOWER policies which includes Monitoring tobacco use and prevention policies, Protecting people from tobacco smoke, Offering help to quit tobacco use, Warning about the dangers of tobacco, Enforcing bans on tobacco advertising, promotion and sponsorship, Raising taxes on tobacco..[22] Incorporating the comprehensive tobacco control program in the COVID 19 management, will aid in reduction of new COVID-19 infections and promote the younger generation to quit tobacco at an early stage.

The GYTS reports the effective tobacco control policies existing among this population in India. The reduction to SHS reported in the surveys is a sign wherein, the best use of tobacco control measures is seen. [23] The messages related to the harm of SHS can further consist of information about how SHS not only cause tobacco-related diseases among second-hand smokers but also makes them prone to CVOD-19. The age group knowing the importance of banning smoking in public places can be exploited to also inform them of the risk of transmission of COVID-19 in public places and increase the following of social distancing, and avoidance of mass gatherings, and places used for tobacco-related activities like the smoking rooms, restaurants and bars.

The increased use of cessation services and the attempts to quit in this age groups denotes the need for sound tobacco cessation services to be in place. The tobacco cessation services can include information about the COVID-19 and tobacco as a risk factor and the negatives outcomes due to it can be elaborated in the behavioural counselling.[6] The most effective tobacco control measure is the anti-tobacco mass media campaigns [24] with wide coverage in India. The adolescents reported in the GYTS demonstrated the increased viewing of such campaigns. Therefore, future mass media campaigns could include information related to COVID-19 and the risk of tobacco use, negative outcomes and burden of the disease due to tobacco, and stories of COVID-19 patients who had consumed tobacco.

The access to tobacco products among this population is the key reason for them to initiate the habit. Therefore, the strict enforcement of no tobacco policies in schools [25] along with information on use of tobacco as a risk factor to COVID-19 can be incorporated. This in turn will help to curb the initiation of the habit thereby reducing the future prevalence among this population. Under the national tobacco control programme, the promising inclusion of tobacco-related information in the school curriculum [25] is another mode that can be further exploited to include COVID-19 related information. The risk of tobacco consumers being prone to coronavirus infection and the preventive factors related to it can encourage the younger generation to have safe and good health practices.

The present study prominently denotes the need to include the younger generation in COVID-19 prevention and management strategies to reduce the future burden of the disease. The study also directs the need to carry out the national representative survey GYTS among the adolescent to have a better picture of the current tobacco use and now to include COVID 19 questions to the standard GYTS tools. This would aid in the incorporation of tobacco control measure in the coronavirus disease protocols. The cumulative advantage of including the tobacco control methods in the modalities for COVID 19 will be a rewarding strategy to improve and strengthen the health care system of the country.

\section{Reference:}

1. Lang AE, Yakhkind A. Coronavirus Disease 2019 and Smoking: How and Why We Implemented a Tobacco Treatment Campaign. Chest [Internet].

2020;158(4):1770-6. Available from: https://doi.org/10.1016/j.chest.2020.06.013

2. Ahmad S. A Review of COVID-19 (Coronavirus Disease-2019) Diagnosis, Treatments and Prevention. Eurasian J Med Oncol. 2020;4(2):1 16-25.

3. Vardavas Cl, Nikitara K. COVID-19 and smoking: A systematic review of the evidence. Tob Induc Dis. 18(March):1-4.

4. Gaiha SM, Cheng J, Halpern-Felsher B. Association Between Youth Smoking, Electronic Cigarette Use, and COVID-19. J Adolesc Heal 67. 2020;67(4):519-23.

5. Gülsen A, Yigitbas BA, Uslu B, Drömann D, Kilinc O. The effect of smoking on COVID-19 symptom severity: Systematic review and meta-analysis. medRxiv. 2020;2020.

6. Gupte H, Mandal G, Jagiasi D. How has the COVID-19 pandemic affected tobacco users in India: Lessons 
from an ongoing tobacco cessation program. Tob Prev Cessat. 2020;6(September):1-5.

7. Kalan ME, Ghobadi H, Taleb Z Ben, Adham D, Cobb CO, Ward KD, et al. COVID-19 and beliefs about tobacco use: an online cross-sectional study in Iran. Environ Sci Pollut Res. 2020;

8. Gupta AK, Nethan ST, Mehrotra R. Tobacco use as a well-recognized cause of severe COVID-19 manifestations. Respir Med [Internet]. 2021;176(November 2020):106233. Available from: https://doi.org/10.1016/j.rmed.2020.106233

9. Zhang H, Ma S, Han T, Qu G, Cheng C, Patrick J. Association of smoking history with severe and critical outcomes in COVID-19 patients: A systemic review and meta-analysis. 2021;(43):101313.

10. National Centre for Disease Control (NCDC) Graphical illustration of data from COVID-19 cases in India. 2021;2021. Available from: https://www.ncdc.gov.in/dashboard.php

11. Rawat R, Thakur A. Prevalence of Tobacco Use Among School Going Adolescents in Bhopal. J Evol Med Dent Sci. 2015;4(05):815-20.

12. Tata Institute of Social Sciences and Ministry of Health and Family Welfare Government of India. Global Adult Tobacco Survey GATS 2 India 2016-2017 Report [Internet]. Ministry of Health and Family Welfare, Government of India. 2017. 362 p. Available from: https://mohfw.gov.in/sites/default/files/Globaltobaco June2018.pdf

13. Hamid H, Abid Z, Amir A, Rehman TU, Akram W, Mehboob T. Current burden on healthcare systems in low- and middle-income countries: recommendations for emergency care of COVID-19. Drugs Ther Perspect [Internet]. 2020;36(10):466-8. Available from: https://doi.org/10.1007/s40267-020-00766-2

14. Rekha M. COVID-19: Health Care System in India. Heal Care Curr Rev [Internet]. 2020;(S1):262. Available from: https://www.longdom.org/open-access/covid19health-care-system-in-india-58032.html

15. Warren CW. The Global Tobacco Surveillance System. Tob Control. 2006;15(SUPPL. 2):1-4.

16. Global Youth Tobacco Survey (GYTS) and Global School Personnel Survey (GSPS), India 2003- 2009. Ministry of Health and Family Welfare Government of India. [Internet]. 2009. Available from:

https://nhm.gov.in/NTCP/Surveys-ReportsPublications/GYTS_and_GSPS_India-2003-2009.pdf
17. GYTS. Global Youth Tobacco Survey Factsheet. India 2006; 2006; Available from:

https://www.who.int/publications/m/item/2006-gytsfact-sheet-india

18. GYTS. Global Youth Tobacco Survey Factsheet. India 2009; [Internet]. 2009. Available from:

https://www.who.int/fctc/reporting/Annexoneindia.p df

19. Reddy KS, Gupta PC. Report on Tobacco Contro in India. Ministry of Health and Family Welfare 2004. Government of India-New Delhi. 2004;43-7. Available from:

https://www.who.int/fctc/reporting/Annex6_Report_o n_Tobacco_Control_in_India_2004.pdf

20. Sinha D, Gupta P, Reddy K, Prasad V, Rahman K, Warren C, et al. Linking Global Youth Tobacco Survey 2003 and 2006 Data to Tobacco Control Policy in India. 2008;78(7):7-12.

21. Gajalakshmi V, Kanimozhi CV. A Survey of 24,000 Students Aged 13-15 Years in India: Global Youth Tobacco Survey 2006 and 2009. Tob Use Insights. 2010;3:1179173×1000300.

22. Operational Guidelines, National Tobacco Control Programme, National Tobacco Control Cell Ministry of Health and Family Welfare Government of India [Internet]. 2015. Available from:

https://nhm.gov.in/NTCP/Manuals_Guidelines/Operati onal_Guidelines-NTCP.pdf

23. World Health Organization. WHO Report on the Global Tobacco Epidemic, 2019: Offer Help to Quit Tobacco Use. Geneva: WorldHealth Organization; 2019. [Internet]. 2019. Available from: http://www.who.int/tobacco/mpower/offer/en/

24. Saxena A, Sharma K, Avashia V. Assessment of Tobacco Control Policy in India: An Evaluation using the World Health Organization MPOWER Framework. Indian J Community Med. 2020;45(4):543-5.

25. Government of India. Ministry of Health and Family Welfare. Directorate General of Health Services. National Tobacco Control Programme. Manual on tobacco control in schools. [Internet]. Available from: https://ntcp.nhp.gov.in/assets/document/Guidelinemanuals/Manual-on-Tobacco-Control-in-Schools.pdf 